\author{
Y. Bertrand ${ }^{1 *}$, F. Pleijel ${ }^{2}$ \& \\ G. W. Rouse ${ }^{3}$ \\ ${ }^{1}$ Muséum national d'Histoire \\ naturelle, Département \\ Systématique et Evolution, \\ CNRS UMR 7138, \\ 'Systématique, Adaptation, \\ Evolution', 43, rue Cuvier, 75231 \\ Paris Cedex 05, France and \\ Department of Natural Sciences, \\ Södertörn University College, \\ SE-141 89 Huddinge, Sweden \\ 2 Department of Marine \\ Ecology, Tjärnö Marine \\ Biological Laboratory, Göteborg \\ University, SE-45296 \\ Strömstad, Sweden, and \\ Muséum national d'Histoire \\ naturelle, Département \\ Systématique et Evolution, \\ CNRS UMR 7138, \\ 'Systématique, Adaptation, \\ Evolution', 43, rue Cuvier, \\ 75231 Paris Cedex 05, France \\ 3 South Australian Museum Nth \\ Terrace, Adelaide, SA 5000, and \\ Environmental Biology, \\ Adelaide University SA 5005, \\ Australia
}

submitted December 2003

accepted July 2005

\section{Taxonomic surrogacy in biodiversity assessments, and the meaning of Linnaean ranks}

\begin{abstract}
The majority of biodiversity assessments use species as the base unit. Recently, a series of studies have suggested replacing numbers of species with higher ranked taxa (genera, families, etc.); a method known as taxonomic surrogacy that has an important potential to save time and resources in assesments of biological diversity. We examine the relationships between taxa and ranks, and suggest that species/higher taxon exchanges are founded on misconceptions about the properties of Linnaean classification. Rank allocations in current classifications constitute a heterogeneous mixture of various historical and contemporary views. Even if all taxa were monophyletic, those referred to the same rank would simply denote separate clades without further equivalence. We conclude that they are no more comparable than any other, non-nested taxa, such as, for example, the genus Rattus and the phylum Arthropoda, and that taxonomic surrogacy lacks justification. These problems are also illustrated with data of polychaetous annelid worms from a broad-scale study of benthic biodiversity and species distributions in the Irish Sea. A recent consensus phylogeny for polychaetes is used to provide three different family-level classifications of polychaetes. We use families as a surrogate for species, and present Shannon-Wiener diversity indices for the different sites and the three different classifications, showing how the diversity measures rely on subjective rank allocations.
\end{abstract}

Key words Taxonomic surrogacy, biodiversity, Polychaeta, Linnaean ranks
During the last decade the measurement of biological diversity (biodiversity) has emerged as a major discipline in biology, with an immense practical importance in directing our efforts to minimise human-induced impoverishment of life on earth (e.g., Purvis \& Hector, 2000). In an overwhelming majority of studies aiming to measure biodiversity, the species rank holds a central position (Gaston, 2000). However, accurate identification of species often requires considerable expertise and is, for many taxa, both a difficult and timeconsuming procedure. The lack of taxonomic expertise, particularly in areas of high diversity, and the expense involved in detailed surveys, has resulted in several different attempts to find reliable surrogates for species diversity. A number of authors (e.g. Raup, 1979; Andersen, 1995; Balmford et al., 1996a, 1996b, 2000; Gaston \& Williams, 1993; Lee, 1997; Warwick, 1988; Williams \& Gaston, 1994) have suggested that species numbers need not be assessed directly, but can be estimated indirectly by counting higher ranked taxa, such as genera, families or orders - an idea that also has been

*Corresponding author. Email: Yann.Bertrand@sh.se developed within palaeontology (e.g. Raup, 1979; Raup \& Sepkoski, 1984). The method is usually referred to as 'taxonomic surrogacy'. Needless to say, the gains in time and resources of using higher taxa instead of species would be considerable.

We here examine the method of taxonomic surrogacy and its relationships to the Linnaean ranks, and conclude that the method suffers from severe shortcomings, and appears to be founded on misunderstandings of the relationship between the phylogenetic components of diversity, and how these components are represented in classifications.

\section{Exchanging species for higher taxa}

The 'taxonomic surrogacy' approach is based on the premise that there are predictable relationships between species and higher taxonomic ranks such as genera and families. Furthermore, to be of practical value, the higher taxon counts must be able to predict species richness with a reasonable amount of precision. Suppose that we know the species richness for a number of sites. Based on existing classifications of the 


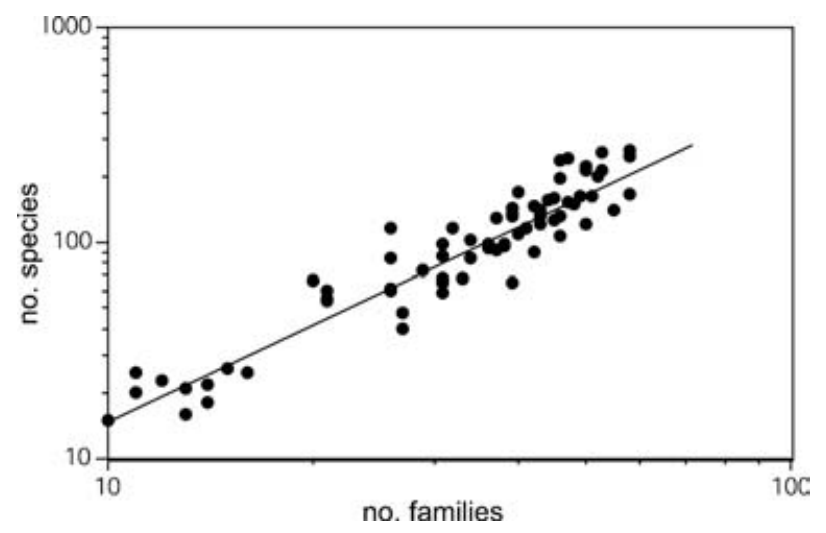

Figure 1 An example of species/family richness relationships (log transformed) in plants from Gentry (1988). The species/higher taxon exchange are assessed from the regression line. The figure is reproduced from Williams et al. (1991).

included taxa we can, for each site, compare species richness with, say, family richness. These relationships can be illustrated in a diagram with number of species as one axis and number of families as the other (Fig. 1). Subsequently this regression can be extrapolated for other sites and other taxa, where the species richness then is estimated from the family richness.

\section{In palaeontology}

Within palaeontology the taxonomic surrogacy approach was introduced because of the lack of species-level information in the fossil record. Based on a generally low probability of fossilisation, it is more likely that higher taxa will be represented in the samples than species. Raup (1979), in one example, estimated that $96 \%$ of marine invertebrate species went extinct in the Late Permian. The calculations were based on an observed disappearance of $52 \%$ of the marine invertebrate family-ranked taxa at the transition between the Permian and Triassic periods. Using a rarefaction plot of species-family relationships in a classification of Recent Echinoidea (sea urchins), Raup calculated at first that $52 \%$ of the extant echinoid families contain $96 \%$ of the species. Assuming comparable relationships between the classifications of Recent and Fossil taxa, as well as between echinoids and all marine invertebrates, he then estimated that $96 \%$ of the marine species may have gone extinct during that period. Applying similar arguments, Raup \& Sepkoski (1984) used fossil marine vertebrates, as well as invertebrates, in an attempt to demonstrate that extinctions since the Mid-Permian show a periodicity of about 26 million years. Thus, it is argued, the global variation of life on earth is traceable by following the changes in the number of families or genera during time (Roy et al. 1996). This, however, implies that families or genera contain a constant number of species across all major groups and that old data can be assimilated with new, even though they may be collected with different taxonomic standards (Jackson \& Johnson, 2001). At present the most complete databases for fossils are Sepkoski's (1992) compilation of marine invertebrate families and genera, the new database of Alroy et al. (2002) which completes and modifies the one by Sepkoski, and Benton's (1993) compilation of plant and animal families. These data at higher ranks level have been used to investigate issues such as correlations between extinction and origination rates, searches for fractal patterns in diversity caused by the internal dynamics of the biosphere, or even for evidence for external causes of extinctions, such as meteorite impacts (Solé et al., 1997; Hewzulla et al., 1999; Newman \& Eble, 1999; Kirchner \& Weil, 2000).

For recent biodiversity studies, the most obvious and important application is within conservation biology and in studies of human-induced perturbations.

\section{In community perturbation studies}

One early empirical study by Warwick (1988), suggested that higher taxa rather than species can be used to detect pollution effects in marine environments. From analyses of five different data sets on meio- and macrofauna from different localities in northern Europe, he concluded that species taxa could be exchanged for family taxa without loss of important information. Olsgard et al. (1998a; 1998b) applied an essentially similar methodology in studies of pollution effects on macrobenthic communities in the North Sea. This approach, also known as 'Taxonomic sufficiency' (identifying organisms only to a level of taxonomic resolution sufficient to satisfy the objectives of a study; see e.g., Pik et al. 1999), has been applied for detecting pollution effects on faunal communities' changes in east Antarctica (Thompson et al. 2003), where the family level reflected the changes in the species composition. However, class and phylum level did not retain assemblages' differences, which contrasts with the findings of Olsgard et al. (1998a, 1998b). Many more studies have tested taxonomic sufficiency in the assessment of environmental impacts, but demonstrate a low levels of agreements in the choice of appropriate taxonomic ranks. Indeed Terlizzi et al. (2003) called attention to the difficulty to generalise the conclusions from each study to other assemblages and environments. In addition, the relationships between different ecological measures and the taxonomic levels are not uniform, as illustrated by Pagola-Clarte et al. (2002) in a monitoring study of macrozoobenthic organisms in the Northern Iberian Peninsula. While analyses based on abundance data lost more information when the taxonomic level increased (from species up to phylum), this trend was not perceptible for data on cover estimates or biomass measures. This result on abundance patterns was not corroborated by Olsgard \& Somerfield (2000) in their study of pollution effects on benthic communities in North Sea. They showed that family richness was useful for monitoring the changes in abundance, but only when the community structure resulted from a strong spatial gradient like the one induced by heavy pollution. Hence they recommended restricting the taxonomic sufficiency method to routine pollution monitoring when the species baseline studies have already been completed.

In another study, Warwick \& Clarke (1995) introduced a biodiversity measure called 'taxonomic distinctness $(\Delta)$ ', based on components of species abundance and taxonomic 
diversity linked to the Linnaean ranks. The latter component was calculated such that congeneric species were given weight 1 , species of different genera but in the same family weight 2 , etc., up to species of different classes but same phylum, which were given weight 6 . This constitutes an example where ranks are treated as equivalent units in an explicit, quantitative fashion. The indices of taxonomic diversity (Warwick \& Clarke 1995), average taxonomic distinctness (Clarke \& Warwick, 1998), and variation in taxonomic distinctness (Clarke \& Warwick, 2001) have been developed from the concept of taxonomic distinctness. These indices all rely on the assumption that in the absence of phylogenetic studies, the taxonomic relations in the Linnaean classification provide a good surrogate for the evolutionary relationships (Clarke \& Warwick, 2001). Taxonomic distinctness has been used for investigating historical evolution of ecological communities as well as the disturbance level of ecosystems (Piepenburg et al., 1997). Furthermore, it has been proposed to apply the taxonomic distinctness for determining the extent to which ecological assemblages are able to resist change, and thereby providing a natural resources management tool (Rogers et al., 1999), as well as a mean for monitoring natural perturbations (Brown et al., 2002) and pollution effects.

\section{In conservation studies}

Gaston \& Williams (1993) suggested that the higher taxon approach can be applied within conservation in order to predict species richness. The predictive power of the method was assessed by Williams \& Gaston (1994) in a study on several different taxa and regions. They favoured this approach, but raised the issues of bias due to sampling efforts, rank choices, atypical regions, and uneven taxonomic treatments. Andersen (1995) also questioned the surrogacy method based on studies of species versus genus richness in Australian ants. He found that the potential biases outlined by Williams \& Gaston (1994) modified the ratio between species and higher taxa, and thus were highly influential on the final species estimates.

Balmford et al. (1996a) used species, genera and families across several major taxonomic groups. Although they in many cases found close relationships between species and higher taxa, the actual precision for the estimates of species richness was often surprisingly low for those sites where the gain would be largest. They concluded that taxonomic surrogacy represents a promising approach, but that the higher rank to be surveyed needs to be carefully selected. These results were corroborated by Eduardo \& Grelle's (2002) study of correlations between higher-taxon surveys and specific richness of Neotropic mammals. From the four examined orders (Didelphimorpha, Chiroptera, Rodentia and Primates), only one, Primates, exhibited a significant correlation between species and family richness that could allow for surrogacy. In contrast, Eduardo and Grelle observed higher correlations when considering genus data for all the four groups altogether, although within each group the strength of the relations varied substantially.

The existence of significant correlations between species richness and higher taxon richness has been demonstrated by Doerries \& Van Dover (2003) for deep-sea mussel beds at the generic, family and order levels. Class richness was a poor surrogate in these communities. However, the high correlations reported in this study are probably due to unusual taxonomic assemblages demonstrating global low species/higher taxa ratios : species/genera varies between 1.1 and 1.3, while species/ families were between 1.3 and 1.7. These values should be considered in regard to our Irish Sea case study where we observed a species/genus of 1.9 and a species/families of 6.5. Moreover, the authors attributed the strong correspondences between taxonomic levels to homogeneous distributions of species inside genera and families. As a consequence these findings should be used with caution when extrapolated to other taxa.

Balmford et al. (1996b) and Balmford et al. (2000) avoided the accuracy problem. They suggested classifying the sites according to the higher taxa present; thus species taxa need not be estimated. They assumed that local patterns of species richness were mirrored at genus, family and order levels, and suggested that the method could be applied to design reserve networks. Another study performed by Fjeldså (2000) used occurrences of Andean species and genera of birds in an extended set of variable ecoregions. Genus level data identified some species-rich hotspots in localities characterised by complex tropical habitats with numerous genera, but overlooked other important sites in more uniform habitats and where many species were distributed in fewer genera. The author concluded that genus data as a surrogate had poor efficiency for the design of conservation areas networks. Similar results were reported by La Ferla et al. (2002) when assessing the use of higher taxa for predicting patterns of angiosperm species richness in Sub-Saharan Africa. Although genera performed better than families, order and subclasses, they failed to report the important species hotspot constituted by the Cape Region. Therefore La Ferla et al. advised caution when selecting areas of highest conservation priority on the ground of taxa above the genus level.

Another approach to biodiversity conservation is the focus on reserve networks. Balmford et al. (1996a) and Balmford et al. (2000) identified such networks based on the complementarity in higher taxa between different areas. The complementarity principle ensures that the selected areas represent all the higher taxa at least once. However this approach was also challenged on empirical grounds by van Jaarsveld et al. (1998). The authors have used data from a wide range of South African plants and animals (mammals, birds, plants, butterflies, termites, antlions, scarab beetles and buprestid beetles) to compare the complementary sets resulting from the use of genera and families with the networks representing the species. With the removal of termites and antlions which were either poorly surveyed or represented by few species, the average overlap was $27.7 \%$ for genera and species-based sets and $4.5 \%$ for families and species. Thus this study provided support against the congruence in complementarity across taxonomic levels.

There have been ambiguous results in most of the fields where taxonomic surrogacy is applied, and in order to better understand the fundaments of the method, we first address issues relating to taxonomic practice in rank assignments. 


\section{Classification and the meanings of ranks}

The Linnaean system is regulated by different nomenclatural codes for plants, animals, bacteria and viruses. There are a number of differences between the codes, but they all have taxa referred to ranks (genus, family, etc.). However, the concept of taxonomic ranks has varied through history and continues to mean different things among contemporary systematists (e.g. Minelli, 2000; Stevens, 1994). For some they represent a notion that has an actual correspondence in nature, implying that ranks can be empirically examined and have a separate existence from taxonomists' minds. For others they are subjective devices, which only serve as a device to memorise classifications. In addition, ranks are sometimes linked to characters, where, for example, one set of characters is considered appropriate for generic delineations, and another set for family delineations. Conceptually, this view contrasts with that of ranks being linked to cladogram topologies and relationships among taxa, where, for example, kingdoms and phyla refer to basal lineages of the tree of life.

Among early systematists, Linnaeus believed in the number five as fundamental, and subdivided each kingdom into the five ranks: variety, species, genus, order and class (e.g. Ereshefsky, 2001). Of these, the genus held a special position in nature; genera were the direct results of divine creation and the taxonomists' task was to discover them. For the other ranks he was less clear and shifted views during his life, but tended to regard them as less natural than the genera, and seemed to apply them more for practical purposes (e.g. Mayr, 1982). Lamarck, at least in his earlier publications (e.g. Lamarck, 1778), viewed any taxonomic groupings (and therefore also ranks) as artificial subdivisions of a continuous scala naturae (e.g. Stevens, 1994). The species constituted no exception, and the only non-arbitrary unit which he recognised was individual specimens (Lamarck, 1802). In making these arbitrary subdivisions, Lamarck also, for practical reasons, suggested that size be taken into consideration, such that genera, for example, should not include too many species (Stevens, 1994). The mid-19th century botanists Bentham and Hooker went further on this path and delineated angiosperms such that most groups did not have more than 12 directly subordinated taxa, but also included 'similar amounts' of morphological variation (Stevens, 1997). Stevens (1994) and Minelli (2000) provide further entries into the literature on the various meanings of ranks through history.

Also today there is a variety of views on the meanings of ranks. For Dubois (1988), for example, the genus refers to groups of potentially hybridising species, and for Bock \& Farrand (1980) it refers to ecological and morphological entities. The zoological rank phylum is often (e.g. Brusca \& Brusca, 1990) identified as units of animals with similar 'bauplans' (body plans). These views emphasise a connection between sets of characters and particular ranks. Hennig (1966), in contrast, suggested coupling the ranks of taxa, not to characters, but to their absolute age, an idea which more recently has been taken up by Sibley \& Ahlquist (1990) and Avise \& Johns (1999).
However, the dominant view among phylogeneticists of today, we believe, is that supraspecific ranks have hierarchical rather than character- or age-based connotations, and that they are employed to communicate information about inclusiveness and/or exclusiveness. Under that view, of course, concepts such as 'generic characters' or 'family characters' become meaningless. Ranks, on a cladogram with the terminals at the top, attempts to communicate two different kinds of information: vertical and horizontal. The vertical relationships refer to the system of groups within groups (genera within families, families within orders, etc.). The horizontal relationships, however, are much more elusive, and all that actually can be stated within a phylogenetic system is that taxa referred to the same rank are non-overlapping.

Apart from this, the inclusivity of taxa and their rank associations are decided by the individual systematists on a case-by-case basis. This decision is actually quite complex and includes a number of considerations apart from monophyly. One is mnemonic - the groups are often kept small enough to be memorised but large enough to permit generalisations, another is to minimise name changes. In a revision the taxonomist today strives to keep traditional taxon names and their associations as intact as possible, but still referring to monophyletic groups. The rank allocation of any given taxon is thus dictated, not only by phylogenetic concerns to communicate relationships, but also by previous rank allocations of the neighbouring taxa. For example, a new taxon may be referred to a new subfamily because it is nested within a taxon currently referred to a family, and because it is separate from the currently employed subfamilies within the family. In this way, taxonomists decisions on rank placements of taxa are influenced by the practices of the foregoing generation of taxonomists working on their particular group; an influence which successively reaches all the way back to the origins of the taxonomy of the group.

In contrast to ranks such as the genus and the family, there seems to be a consensus among a majority of systematists that species hold a special role in nature. Most currently employed species concepts are based, either on reproduction, such as the 'biological species concept' (e.g. Mayr, 1940), or on characters, such as the 'morphological species concept' (e.g. Cronquist, 1978) and the 'diagnosable species concept' (e.g. Nixon \& Wheeler, 1990), and de Queiroz in two recent studies $(1998 ; 1999)$ has argued that many of these concepts constitute criteria rather than concepts, and that they actually converge toward a largely similar notion, 'the general lineage species concept'. Following these views, species taxa may, by and large, constitute comparable units (but see Mishler, 1999; Pleijel, 1999; Pleijel \& Rouse, 2000a; 2000b for differing views).

The practical effects of this heterogeneity in views on supraspecific ranks can be visualised from diagrams illustrating taxa of one rank and how many directly subordinated taxa they contain (e.g. the number of genera per family in a given classification). For example, in the late 18th century the number of genera per family in angiosperms had a maximum of between 1 and 25 genera, with a single monotypic family (Jussieu, 1789) (Fig. 2a). Today's distribution instead 

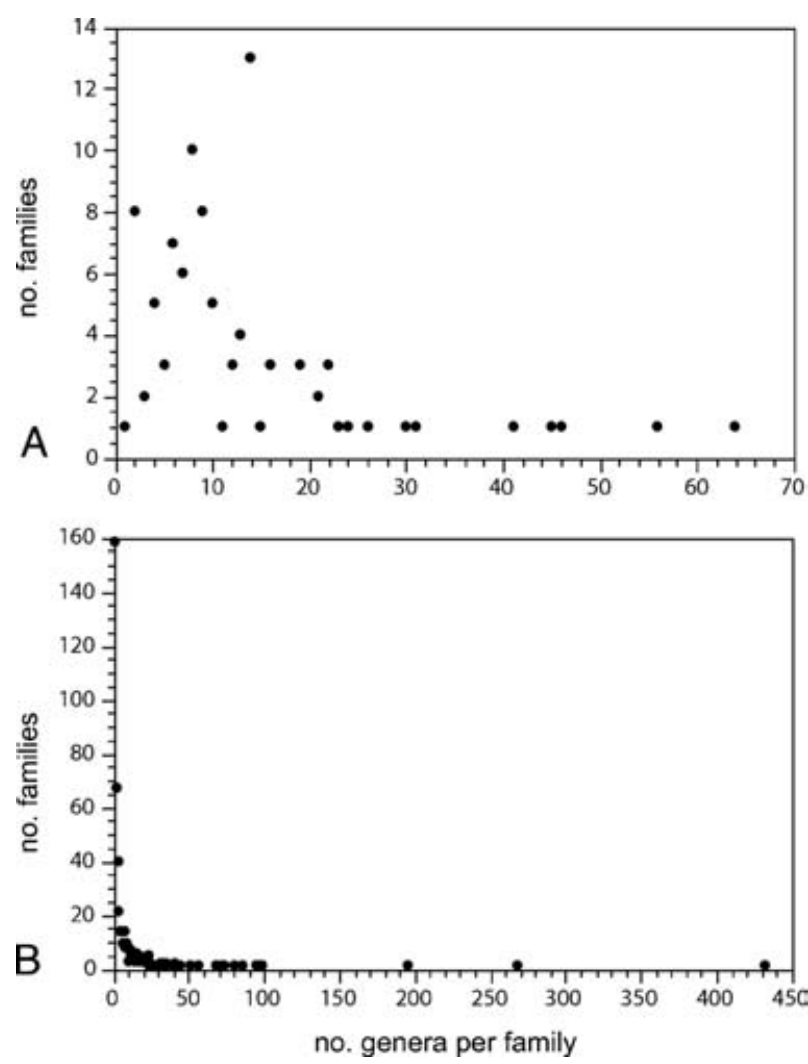

Figure 2 The relationship between number of families and number of genera of plants from A. Jussieu's (1789) classification, and $B$ a current classification ('hollow curve' shaped) as obtained from the PLANTS database (USDA, NRCS. 2001. The PLANTS Database, Version 3.1 (http://plants.usda.gov). National Plant Data Center, Baton Rouge, LA 70874-4490 USA). The two curves reflect different practices in the size delineation of taxa.

corresponds to what is known as the 'the hollow curve' (Willis, 1922) (Fig. 2b), and is found for most organisms at any level within the hierarchy of classification (Dial \& Marzluff, 1989). This kind of distribution appears to have emerged in the 20th century as a result of a trend to split taxa into smaller ones (Walters, 1961). So contemporary classifications are characterised by a preponderance of monotypic taxa and a long tail of relatively few large ones (Fig. 2b). Because of the increasing number of small taxa, families become more similar in content to genera, and genera more similar to species. Some authors, such as (Clayton, 1971), have argued that the hollow curve stems from evolutionary patterns rather than from taxonomic practice. It has been ascribed to combinations of speciation and extinction events, where the small taxa are seen as recent and not very diverse groups or relicts, and the larger ones as older and more diverse (see also Chamberlin, 1924; Dial \& Marzluff, 1989; Hilbig, 1995; Holman, 1996).

The important conclusion from this non-exhaustive list of the various interpretations of ranks is that our current classifications are based on mixtures of many different concepts and practices. Furthermore, this would be the case even if all taxa referred to monophyletic groups. Taxa referred to the same ranks do not constitute single classes of objects: a taxon may be referred to a genus or family rank because of phylogenetic relationships, but also because the neighbouring taxa traditionally are referred to some ranks, or because it has a certain set of characters, or because it includes a certain number of subordinated taxa, or because it displays morphological (or other) gaps which separates it from other taxa. This begets the question: how can one genus or one family be the equivalent to another genus or family?

\section{Polychaetes from the Irish Sea: an example}

In order to provide an illustration of the problems involved in relationships between species and higher rank taxa, we present a case study on marine polychaetes. This group was selected for two reasons: we had access to the necessary information for creating different, plausible classifications based on a single phylogeny, and there is a recent and appropriate case study on benthic invertebrates (including polychaetes) from the Irish Sea (Mackie et al., 1995). This publication includes quantitative data from duplicate samples of benthic macrofauna from 51 different stations. The great majority of the polychaete specimens were determined to species level, and both identifications and family allocations are up-to-date and follow the family delineations as presented by, e.g., Rouse \& Fauchald (1997).

We created two new classifications based on the polychaete tree topology in Rouse \& Pleijel (2001), a study which includes a 'metatree' derived from all available phylogenetic analyses carried out on polychaetes. We chose to compare the number of species with the number of families in the samples. Comparing species to genera would have yielded little gain since the majority of the genera are represented in the study by single species only, and ranks above the family level are simply too few to retain any information. The 49 families as employed by Mackie et al. (1995) constitute the 'standard' delineation. From the polychaete tree we then created two new family classifications, one 'lumper' with 15 more inclusive families, and one 'splitter' with 90 less inclusive families. Both the classifications and the tree contain several hundred taxa and are too extensive to be reproduced here, though they are available as supplementary data available on Cambridge Journals Online at: http://www.journals.cup.org/ abstract_S1477200005001908 together with full descriptions of species and family allocations in the three different classifications (see Table 1 for an example of the method). Interestingly, the lumper classification in many respects resembles some of the early 19th century classifications (e.g. Fauchald \& Rouse, 1997). The splitter classification has no precedence in the literature. Of more importance, however, is that both classifications are entirely plausible, depending on slightly different views on the inclusiveness of family group taxa in the tradition of polychaete taxonomy.

At first, family richness for each station was plotted against species richness based on the lumper, standard and splitter classifications, respectively (Fig. 3a). The amount of 


\begin{tabular}{llll}
\hline & & Families & \\
\cline { 2 - 4 } Species & Splitter & Standard & Lumper \\
Aphrodita aculeata & Aphroditidae & Aphroditidae & Aphroditidae \\
Acholoe squamosa & Acholoidae & Polynoidae & ib. \\
Gattyana cirrosa & Harmothoidae & ib. & ib. \\
Harmothoe fragilis & ib. & ib. & ib. \\
Harmothoe fraserthomsoni & ib. & ib. & ib. \\
Harmothoe glabra & ib. & ib. & ib. \\
Harmothoe impar & ib. & ib. & ib. \\
Harmothoe zetlandica & ib. & ib. & ib. \\
Malmgrenia andreapolis & ib. & ib. & ib. \\
Malmgrenia mcintoshi & ib. & ib. & ib. \\
Polynoe scolopendrina & Polynoidae & ib. & ib. \\
Lepidonotus squamatus & Lepidonotidae & ib. & ib. \\
Subadyte pellucida & Arctonoidae & ib. & ib. \\
Pholoe tuberculata & Pholoidae & Pholoidae & ib. \\
Pisione remota & Pisionidae & Sigalionidae & ib. \\
Sthenelais boa & ib. & ib. & ib. \\
Sthenelais limicola & ib. & ib. & ib. \\
Sthenelais zetlandica & ib. & ib. & ib. \\
\hline
\end{tabular}

Table 1 Part of the three different family delineations for the case study on polychaetes from the Irish Sea. The actual number of terminals amounts to 321 , and only a small portion is provided here (the scale-worms), serving as an explanation of the procedure. A complete list is available as supplementary data on Cambridge Journals Online at: http://www.journals.cup.org/abstract_S1477200005001908 (see Table 1 therein). Note that none of the newly introduced family names are intended to be valid according to the rules of zoological nomenclature.

difference between the two extreme regressions, represented by the lumper and the splitter lines, gives an illustration of how the number of estimated species can vary depending on the underlying classification. It should be noted that none of our polychaete classifications can be stated to be more 'correct' than the other in terms of how they reflect the polychaete tree, and that most currently employed classifications generally are the composite results of different taxonomist's habits.

We also examined the effect of the classification when specimen numbers are used for diversity measure. There is a large number of indices available; we selected the ShannonWiener index (Shannon \& Weaver, 1949) which generally is used to measure the likelihood to correctly predict the identity of the species of the next individual collected, thus providing an estimate of the species richness and evenness in the samples. In our case, this measure was applied at the family level instead of the species level. (See Tables 2-4 of our supplementary data, referred to above.) The Shannon-Wiener index was chosen simply because it is among the most widely used ones.

The three different delineations yield significantly different results when comparing their diversity indices for the same stations (Fig. 3b). The splitter classification overestimates, and the lumper classification underestimates the local diversity as compared to the standard classification. Accordingly, a site which is judged highly diverse today may come out as much less so following taxonomic revisions and reclassifications. This clearly illustrates the impact of the classifications on the assessment of diversity.

\section{Discussion}

The amount of work needed to map the biodiversity of the earth is indeed enormous, no matter what approaches are chosen. Any measure which might reduce this effort without significant loss of information is therefore of obvious interest. Taxonomic diversity is generally approached by species counts and a species/higher taxon exchange would represent an important decrease in effort.

The surrogacy method has been proposed within three different research fields: (1) palaeontology (e.g. Lee, 1997; Raup, 1979; Raup \& Sepkoski, 1984), (2) conservation biology (e.g. Balmford et al., 2000; Gaston \& Williams, 1993) and (3) marine pollution studies (e.g. Warwick, 1988; Warwick \& Clarke, 1995). All three approaches aim to quantify diversity, but in slightly different fashions. In palaeontology the species-higher taxon relationship in Fossil taxa are assumed to be similar to Recent taxa. Within conservation biology extrapolations are based on species-higher taxon ratios from previous studies. Pollution studies include the same approach as conservation biology, but apply direct counts of higher taxa without reference back to species; in those cases the species estimates are not the actual focus of the study.

A series of authors have noted that the system with ranks may encourage spurious comparisons (e.g. de Queiroz \& Donoghue, 1988), such that taxa referred to the same rank are treated as equivalent units, and we believe this to be a serious 

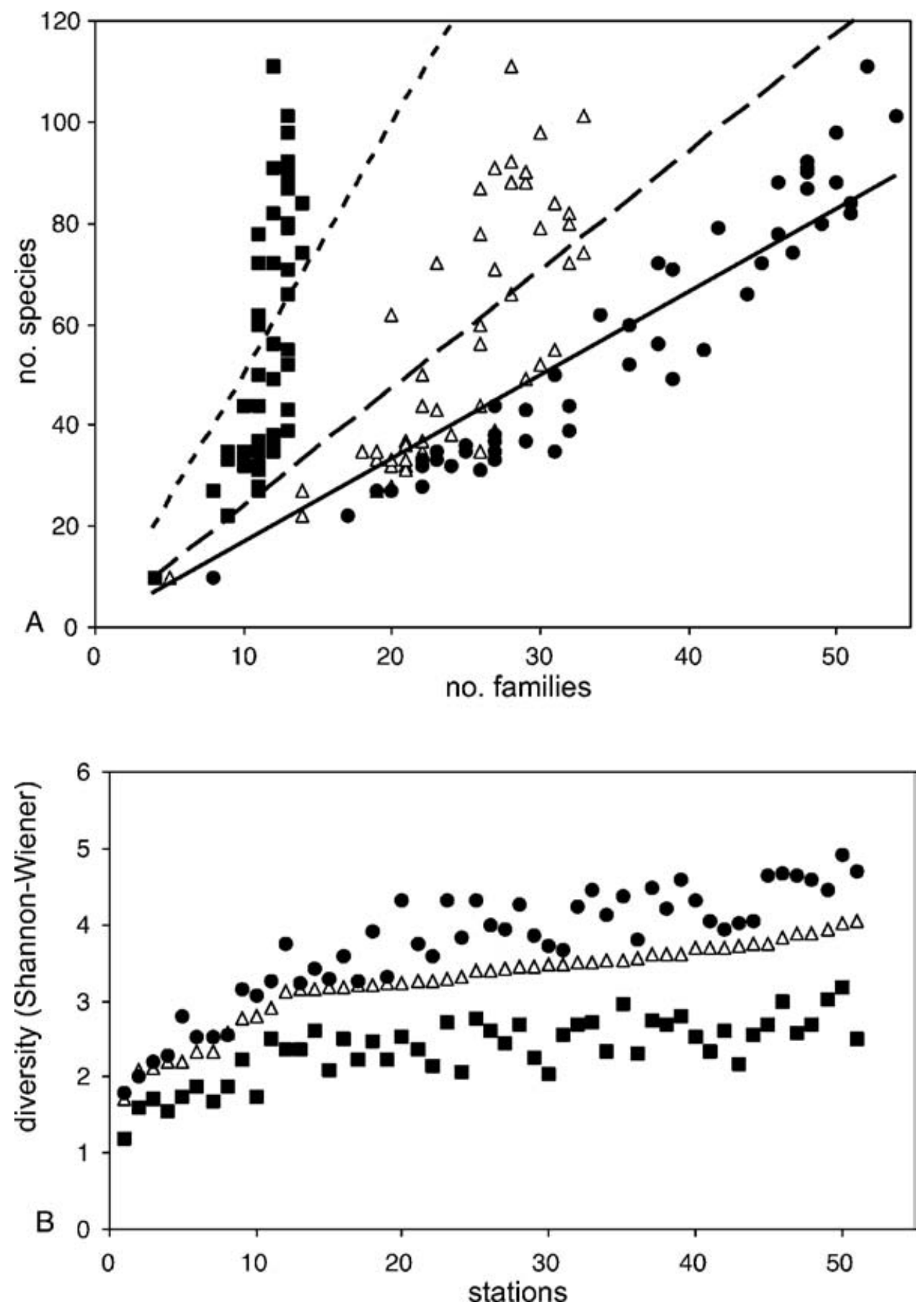

Figure 3 Species/family relationships for a quantitative study of Irish Sea polychaetes (data from Mackie et al., 1995). The three series represent three different families delineations: 'lumper' (squares), 'standard' (triangles) and 'splitter' (circles). A.Relationships between the number of species and families for each of the 51 surveyed stations. The least-squares regression curves associated with each data set are figured. B. Relationships between families delimitations and the Shannon-Wiener index calculated for each station from the families richness to a $\log _{2}$ base. Stations are arranged by increasing Shannon-Wiener index following the median, standard classification. The three family delineations yielded highly significant differences in diversity indices (Kruskal-Wallis rank sum test, $\chi^{2}=72.5831$, d.f. $=2, P<2.2-16$ ), as did the relative over- and underestimates of the 'lumper' and 'splitter' indices (Wilcoxon rank sum test with correction for multiple comparisons, $P=7.9-5$ and $P=1.9-11$, respectively). (For further details, please see our supplementary data, referred to on page 154.)

problem with all three approaches above. As we have seen, rank allocations of taxa are the products of a heterogeneous mixture of ideas through the last 250 years. Furthermore, these rank comparison problems would actually remain even if we were to rename the Tree of Life from scratch, and also if all taxa were monophyletic. One genus in one part of the tree would not even then, in any sense, be equivalent to another genus in another part of the tree, no more (and no less) than the genus Rattus is equivalent to the phylum Arthropoda; these names merely make reference to different historical events. The only 
information present in two taxon names of the same rank is (at best) that they are non-nested.

Still, even without a theoretical foundation, a specieshigher taxon exchange could arguably be defended if the relationships between different ranked taxa proved to have precise, predictive values. However, in this context it should be noted that any plot between different ranked taxa, by necessity, will have some predictive value. This is so simply because, by definition, genera are equal to or more inclusive than species, families are equal to or more inclusive than genera, etc. The key instead lies in the degree of precision of the predictions. High correlations have indeed been reported for species-higher-taxon relationships in several earlier studies (Balmford et al., 1996b; Warwick \& Clarke, 1995), but many studies also report low correlations for various taxa and at various scales (Andersen, 1995; Eduardo \& Grelle, 2002; Fjeldså, 2000). Given the previously explained background on how ranks are applied to taxa in classifications, such heterogeneity is certainly to be expected. And the usefulness of the surrogacy method fails unless we, a priori, know something about the degree of precision in the estimates. This conclusion holds also for the taxonomic sufficiency method, which has a very low level of generalisation, therefore its use must be evaluated on a case by case basis (Pagola-Carte et al. 2002). The method should be restricted to routine monitoring studies when the response of the data to taxonomic generalisation has already been assessed and baseline species studies performed (Terlizzi et al. 2003). On the other hand, the taxonomic distinctness indices have proven to be very effective in their assigned objectives, i.e. detecting community perturbations. However, it should be used with caution for groups where activities of lumper and splitter taxonomists have biased the taxonomic homogeneity (Clarke \& Warwick, 1999), even though this homogeneity is empirically difficult to evaluate.

Within the various surrogacy methods, indicator taxa are particularly popular. Based on the assumption that the richness of a particular taxon, or set of taxa, can mirror global species richness, numerous indicator taxa have been proposed: mammals (Mittermeier, 1988), birds (Bibby et al., 1992), butterflies (Kremen, 1992), plants (Cronk, 1988), etc. However, this surrogacy approach has been severely criticised based on studies which, for a wide range of biotas, exhibits little correspondence in taxon richness (Prendergast et al., 1993; Flather et al., 1996; Dobson et al., 1997; Reid, 1998; Tardiff \& DesGranges, 1998). Despite these negative results, other studies show that indicator taxa may be efficient in the designation of conservation area networks selected by complementary strategies (Ryti, 1992; Csuti et al., 1997; Howard et al., 1998; Andelman \& Fagan, 2000; Reyers et al., 2000; Gladstone, 2002).

Biological diversity is a wide concept which ranges from genes to landscapes and includes compositional, structural and functional aspects (Noss, 1990). One of its components is obviously phylogenetic diversity. Besides being sensitive to numerous biases (Gotelli \& Colwell, 2001; Maddock \& Du Plessis, 1999), simply representing species counts constitutes a poor alternative for assessing biological diversity (Crozier, 1997), even if species group taxa have the advantage of mak- ing up, in general, the smallest taxonomic recognised units. Species counts consider all species as equivalent units and fail to accommodate the historical, phylogenetic components of diversity (May, 1990). Instead, we would suggest that phylogenetic diversity has to be measured from the only actual assessments we have, namely phylogenetic trees, allowing estimates to overcome the problem of rank allocation (Mace et al., 2003). Indeed a phylogenetic frame considers only the historical content of species. Therefore by focusing on the vertical relationships in the tree, the horizontal grouping of taxa into ranks is no longer a problem.

Despite the incorporation of the tree model, rough clade count does not provide a direct answer to an objective biodiversity measure. We have seen that any two clades in the tree of life correspond to two independent historical events and cannot be directly compared unless they are sister taxa. However, the amount of history they contain can be compared in a phylogenetic approach to biodiversity. Two different concepts have been proposed to assess this diversity: the first relying on branch lengths (Faith, 1992, 1994; Walker \& Faith, 1995; Polasky et al., 2001), and the second on information from tree topologies (Vane-Wright et al., 1991; Williams et al., 1991; Vàsquez \& Gittleman, 1998; Posadas et al., 2001). Each method apprehends a single aspect of the phylogenetic tree, hence their comparisons could yield interesting results. Some authors have advocated the use of branch lengths methods (Crozier 1997), which do not rely on any evolutionary clock assumption. Thus these methods could be more appropriate to unravel the information content of phylogenetic trees, allowing users to assess the value of each taxa in terms of historical traits. We should call attention to the fact that Warwick \& Clarke's (1995) taxonomic distinctness indices aim ultimately at assessing a phylogenetic diversity from a phylogenetic tree when available. Taxonomic distinctness calculates distances based on disrcete hierarchical groups and so is conceptually close to a node counting method. Clarke \& Warwick (2001) have compared their indices with a branch lengths biodiversity measure. They demonstrated that unlike the average phylogenetic diversity (the total branch length in the tree divided by the species number), the average taxonomic distinctness is not dependent on the species number and therefore lacks dependence on the sampling effort. Nevertheless this result could be an artefact from the taxonomic distinctness method, which uses very few discrete categories (in their example Clarke \& Warwick used only four levels: species, genera, family and suborder) and needs further investigation. What this means, of course, is that urgent intensive efforts into the development of phylogenetic trees is required since these are sadly lacking for most groups of organisms. Of course the reliability of some phylogenies is still controversial and in our own polychaetes case study we had to use 'the phylogenetic surrogate' that represents 'the metatree'. But things should improve in the near future when more taxa (e.g. Pollock et al. 2002; Zwickl \& Hillis, 2002) and more detailed and complete data (e.g. Kearney, 2002) will be included in analysis. The specieshigher taxon exchange represents one example of how the Linnaean rank system can lead users to unjustified comparisons. The phylogenetic components of diversity need 
to be assessed in terms of tree-thinking, not by means of Linnaean ranks. Nevertheless, how this should be achieved and incorporated with other aspects of diversity remains to be worked out.

\section{Acknowledgements}

We thank R. Debruyne, M. Manuel, M. Härlin, P. Stevens, S. Tillier, and the reviewers B. Clarke and J.C. Poynton for comments on the manuscript, and D. Jutier for statistical advice. GWR is funded by Australian Research Council QEII Fellowship.

\section{References}

Alroy, J., Marshall, C.R., Bambach, R.K., Bezusko, K., FoOte, M., FürSICH, F.T., HANSEN, T.A., Holland, S.M., IVANY, L.C., JABlONSKI, D., JACOBS, D.K., JONES, D.C., KosNiK, M.A., LIDGARD, S., LOW, S., MiLleR, A.I., NovaCK-GotTSHall, P.M., Olszewski, T.D., PATZKowsky, M., RauP, D.M., RoY, K., SEPKOSKI, J.J.J., SOMMERS, M.G., WAGNER, P.J. \& WebBER, A. 2002. Effects of sampling standardization on estimates of Phanerozoic marine diversification. Proceedings of the National Academy of Sciences of the United States of America 98, 62616266.

ANDELMAN, S.J. \& FAGAN, W.F. 2000. Umbrellas and flagships: Efficient conservation surrogates or expensive mistakes? Proceedings of the National Academy of Sciences of the United States of America 97, 5954-5959.

ANDERSEN, A.N. 1995. Measuring more of biodiversity: genus richness as a surrogate for species richness in Australian ant faunas. Biological Conservation 73, 39-43.

AVISE, J.C. \& JoHnS, G.C. 1999. Proposal for a standardized temporal scheme of biological classification for extant species. Proceedings of the National Academy of Sciences of the United States of America 96, 7358-7363.

BALMFORD, A., GREEN, M.J.B. \& MURRAY, M.G. 1996a. Using higher-taxon richness as a surrogate for species richness: I. Regional tests. Proceedings of the Royal Society of London. Series B: Biological Sciences 263, 1267-1274.

BALMFORD, A., JAYASURIYA, A.H.M. \& GREEN, M.J.B. 1996b. Using higher-taxon richness as a surrogate for species richness: II. Local applications. Proceedings of the Royal Society of London. Series B: Biological Sciences 263, 1571-1575.

BALMFORD, A., LYON, A.J.E. \& LANG, R.M. 2000. Testing the highertaxon approach to conservation planning in a megadiverse group: the macrofungi. Biological Conservation 93, 209-217.

BENTON, M.J. 1993. The Fossil Record 2. Chapman and Hall, London.

BibBy, C.J., COLlaR, N.J., CROSBY, M.J., HEATH, M.F., IMBODEN, C., Johnson, T.H., LONG, A.J., STATTERSFIELD, A.J. \& THIRGOOD, S.J. 1992. Putting Biodiversity on the Map: Priority areas for Global Conservation. International Council for Bird Preservation, Cambridge.

Bock, W.J. \& FARRAND JR., J. 1980. The number of species and genera of Recent birds: a contribution to comparative systematics. American Museum Novitates 2703, 1-29.

BROWN, B.E., CLARKE, K.R. \& WARWICK, R.M. 2002. Serial patterns of biodiversity change in corals across shallow reef flats in Ko Phuket, Thailand, due to the effects of local (sedimentation) and regional (climatic) perturbations. Marine Biology 141, 21-29.

BRUSCA, R.C. \& BRUSCA, G.J. 1990. Invertebrates. Sinauer Associates, Inc., Sunderland.

CHAMBERLin, J.C. 1924. Concerning the hollow curve distribution. American Naturalist 58, 350-374.

ClARKE, K.R. \& WARWICK, R.M. 1998. A taxonomic distinctness index and its statistical properties. Journal of Applied Ecology 35, $523-531$.
Clarke, K.R. \& WARWICK, R.M. 1999. The taxonomic distinctness measure of biodiversity: weighting of step lengths between hierarchical levels. Marine Ecology Progress Series 184, 21-29.

Clarke, K.R. \& WARWICK, R.M. 2001. A further biodiversity index applicable to species lists: variation in taxonomic distinctness. Marine Ecology Progress Series 216, 265-278.

Clayton, W.D. 1971. Some aspects of the genus concept. Kew Bulletin 27, 281-287.

CRONK, Q. 1988. Biodiversity. The key role of plants. IUCN/WWF, Gland.

CRONQUist, A. 1978. One again, what is a species? In L. V. Knutson (ed.), Biosystematics in Agriculture pp. 3-20. Allenheld Osmun, New Jersey.

CROZIER, R.H. 1997. Preserving the information content of species: genetic diversity, phylogeny, and conservation worth. Annual Review of Ecology and Systematics 28, 243-268.

Csuti, B., Polasky, S., Williams, P.H., Pressey, R.L., Camm, J.D., KershaW, M., Kiester, A.R., Downs, B., Hamilton, R., HUSO, M. \& SAHR, K. 1997. A comparison of reserve selection algorithms using data on terrestrial vertebrates in Oregon. Biological Conservation 80, 83-97.

DE QueIROZ, K. 1998. The general lineage concept of species, species criteria, and the process of speciation. A conceptual unification and terminological recommendations. In: HowARD, D. J. \& BERLOCHER S. H. Eds, Endless Forms: Species and Speciation pp. 57-75. Oxford University Press, Oxford.

DE QUEIROZ, K. 1999. The general lineage concept of species and the defining properties of the species category. In WILSON, R. A. Ed., Species: New interdisciplinary essays. The MIT Press, Cambridge, Massachusetts. pp. 49-89.

De QueIroz, K. \& DONOGHUE, M.J. 1988. Phylogenetic systematics and the species problem. Cladistics 4, 317-338.

DiAL, K.P. \& MARZLUFF, J.M. 1989. Nonrandom diversification within taxonomic assemblages. Systematic Zoology 38, 26-37.

Dobson, A.P., Rodriguez, J.P., RoberTs, W.M. \& Wilcove, D.S. 1997. Geographic distribution of endangered species in the United States. Science 275, 550-553.

DOERRIES, M.B. \& VAN DOVER, V.L. 2003. Higher-taxon richness as a surrogate for species richness in chemosynthetic communities. Deep-Sea Research 50, 749-755.

Dubois, A. 1988. Le genre en zoologie: essai de systématique théorique. Mémoires du Muséum National d'Histoire Naturelle, Paris 140A, 1-122.

EDUARDO, C. \& GRELLE, V. 2002. Is higher-taxon analysis a useful surrogate of species richness in studies of Neotropical mammal diversity? Biological Conservation 108, 101-106.

ERESHEFSKY, M. 2001. The poverty of the Linnaean hierarchy. A philosophical study of biological taxonomy. Cambridge University Press, Cambridge.

FAITH, D.P. 1992. Conservation evaluation and phylogenetic diversity. Biological Conservation 61, 1-10.

FAITH, D.P. 1994. Phylogenetic pattern and the quantification of organismal biodiversity. Philosophical Transactions of the Royal Society of London Series B-Biological Sciences $\mathbf{3 4 5}$, 45-58.

FaUCHALD, K. \& Rouse, G.W. 1997. Polychaete systematics: past and present. Zoologica Scripta 26, 71-138.

FJELDSÅ, J. 2000. The relevance of systematics in choosing priority areas for global conservation. Environmental Conservation 27, $67-75$.

Flather, C.H., Wilson, K.R., DeAn, D.J. \& MCCOMB, W.C. 1996. Identifying gaps in conservation networks: of indicators and uncertainty in geographic-based analyses. Ecological Applications 7, 531-542.

GASTON, K.J. 2000. Global patterns in biodiversity. Nature 405, 220 227.

Gaston, K.J. \& Williams, P. H. 1993. Mapping the world's speciesthe higher taxon approach. Biodiversity Letters 1, 2-8. 
GENTRY, A.H. 1988. Changes in plant community diversity and floristic composition on environmental and geographical gradients. Annals of the Missouri Botanical Garden 75, 1-34.

GLADSTONE, W. 2002. The potential value of indicator groups in the selection of marine reserves. Biological Conservation 104, 211220.

GOTELLI, N.J. \& COLWELL, R.K. 2001. Quantifying biodiversity: procedures and pitfalls in the measurement and comparison of species richness. Ecology Letters 4, 379-391.

HENNIG, W. 1966. Phylogenetic Systematics. University of Illinois Press, Urbana.

Hewzulla, A., Boulter, M.C., Benton, M.J. \& Halley, J.M. 1999. Evolutionary patterns from mass originations and mass extinctions. Philosophical Transactions of the Royal Society of London. Series B-Biological Sciences 354, 463-469.

HILBIG, B. 1995. Chapter 12. Family Oenonidae Kinberg, 1865. In: Blake, J. A., Hilbig, B. \& ScotT, P. H. Eds, Taxonomic atlas of the benthic fauna of the Santa Maria Basin and western Santa Barbara Channel. Santa Barbara Museum of Natural History, Santa Barbara, pp. 315-339.

HOLMAN, E.W. 1996. The independent variable in the early origin of higher taxa. Journal of Theoretical Biology 181, 85-94.

Howard, P.C., Viskanic, P., DaVENPORT, T.R.B., Kigenyi, F.W., BALTZER, M., DiCKINSON, C.J., LWANGA, J.S., MATTHEWS, R.A. \& BALMFORD, A. 1998. Complementarity and the use of indicator groups for reserve selection in Uganda. Nature 394, 472475.

JACKSON, J.B.C. \& JOHNSON, K.G. 2001. Measuring past biodiversity. Science 293, 2401-2404.

JussiEU, A.-L. 1789. Genera plantarum. Hérissant et Barrois, Paris.

KEARNEY, M. 2002. Fragmentary taxa, missing data, and ambiguity: mistaken assumptions and conclusions. Systematic Biology 51, 369-381.

KIRCHNER, J.W. \& WeIL, A. 2000. Correlations in fossil extinction and origination rates through geological time. Proceedings of the Royal Society of London. Series B: Biological Sciences 267, 13011309.

KREMEN, C. 1992. Butterflies as ecological and biodiversity indicators. Wings 16, 14-17.

La Ferla, B., TAPlin, J., OCKWEll, D. \& LOVETT, J.C. 2002. Continental scale patterns of biodiversity: can higher taxa accurately predict African plant distributions? Botanical Journal of the Linnean Society 138, 225-235.

LAMARCK, J.-B.-P.-A.D.M.D. 1778. Flore françoise. Imprimerie Royale, Paris.

LAMARCK, J.-B.-P.-A.D.M.D. 1802. Recherches sur l'organisation des corps vivans et particulièrement sur son origine, sur la cause de ses développemens et des progrès de sa composition, et sur celle qui, tendant continuellement à la détruire dans chaque individu, amène nécessairement sa mort; précédé du discours d'ouverture du cours de zoologie, donné dans le Muséum national d'Histoire Naturelle. Maillard, Paris.

LEE, M.S.Y. 1997. Documenting present and past biodiversity: conservation biology meets palaeontology. Trends in Ecology and Evolution 12, 132-133.

Mace, G.M., Gittleman, J.L. \& PuRvis, A. 2003. Preserving the tree of life. Science 300, 1707-1709.

MACKIE, A.S.Y., OLIVER, P.G. \& ReES, E.I.S. 1995. Benthic biodiversity in the southern Irish Sea. Studies in marine biodiversity and systematics from the National Museum of Wales. BIOMOR Reports 1, 1-263.

MADDOCK, A. \& DU Plessis, M.A. 1999. Can species data only be appropriately used to conserve biodiversity? Biodiversity and Conservation 8, 603-615.

MAY, R.M. 1990. Taxonomy as destiny. Nature 347, 129-130.

MAYR, E. 1940. Speciation phenomena in birds. American Naturalist 74, 249-278

MAYR, E. 1982. The Growth of Biological Thought. The Belknap Press of Harvard University Press, Cambridge, Massachusetts.
MinelLI, A. 2000. The ranks and the names of species and higher taxa, or a dangerous inertia of the language of natural history. In: GHISELIN, M. T. \& LEVITON, A. E. Eds, Cultures and Institutions of Natural History. Essays in the History and Philosophy of Science. California Academy of Sciences Memoir, San Francisco, pp. 339351.

MISHLER, B.D. 1999. Getting rid of species? In: WILSON, R. A. Ed., Species. New Interdisciplinary Essays. The MIT Press, Cambridge, MA, pp. 307-315.

MitTERMEIER, R.A. 1988. Primate diversity and the tropical forest. Case studies from Brazil and Madagascar and the importance of mega diversity countries. In: WiLson, E. O. \& PETER, F. M. Eds., Biodiversity. National Academy Press, Washington DC, pp. 145-154.

Newman, M.E.J. \& Eble, G.J. 1999. Power spectra of extinction in the fossil record. Proceedings of the Royal Society of London. Series B: Biological Sciences 266, 1267-1270.

NIXON, K.C. \& WHEELER, Q.D. 1990. An amplification of the phylogenetic species concept. Cladistics 6, 211-233.

Noss, R.F. 1990. Indicators for monitoring biodiversity: a hierarchical approach. Conservation Biology 4, 355-364.

OLSGARD, F. \& SOMERFIELD, P.J. 2000. Surrogates in marine benthic investigations - which taxonomic unit to target? Journal of Aquatic Ecosystem Stress and Recovery 7, 25-42.

OlsGARD, F., SOMERFIELD, P.J. \& CARR, M.R. 1998a. Relationships between taxonomic resolution, macrobenthic community patterns and disturbance. Marine Ecology Progress Series 172, 25-36.

OlsGARD, F., SOMERFIELD, P.J. \& CARR, M.R. 1998b. Relationships between taxonomic resolution and data transformation in analyses of a macrobenthic community along an established pollution gradient. Marine Ecology Progress Series 149, 173-181.

Pagola-Carte, S., URKiaga-Alberdi, J., Bustamante, M. \& SaIZSALINAS, J.I. 2002. Concordance degrees in macrozoobenthic monitoring programmes using different sampling methods and taxonomic resolution levels. Marine Pollution Bulletin 44, 63-70.

PiePenburG, D., Voss, J. \& GuTT, J. 1997. Assemblages of sea stars (Echinodermata: Asteroidea) and brittle stars (Echinodermata: Ophiuroidea) in the Weddell Sea (Antarctica) and off Northeast Greenland (Arctic): a comparison of diversity and abundance. Polar Biology 17, 305-322.

PIK, A., Oliver, I. \& BeatTIE, A. J. 1999. Taxonomic sufficiency in ecological studies of terrestrial invertebrates: A case study investigating ant community structure within revegetated agricultural land. Australian Journal of Ecology 24, 555-562.

PLEIJEL, F. 1999. Phylogenetic taxonomy, a farewell to species, and a revision of Heteropodarke (Annelida, Polychaeta, Hesionidae). Systematic Biology 48, 755-789.

PleiJel, F. \& Rouse, G.W. 2000a. A new taxon, capricornia (Hesionidae, Polychaeta), illustrating the LITU ("Least Inclusive Taxonomic Unit") concept. Zoologica Scripta 29, 157-168.

PleiJel, F. \& RouSE, G.W. 2000b. Least-inclusive taxonomic unit: a new taxonomic concept for biology. Proceedings of the Royal Society of London. Series B: Biological Sciences 267, 627-630.

Polasky, S., Csuti, B., Vossler, A. \& Meyers, S.M. 2001. A comparison of taxonomic distinctness versus richness as criteria for setting conservation priorities for North American birds. Biological Conservation 97, 99-105.

Pollock, D.D., ZWICKLE, D.J., MCGuiRe, J.A. \& Hillis, D.M. 2002. Increased taxon sampling is advantageous for phylogenetic inference. Systematic Biology 51, 664-671.

Posadas, P., Miranda Esquivel, D.R. \& CRISCI, J.V. 2001. Using phylogenetic diversity measures to set priorities in conservation: an example from southern South America. Conservation Biology 15, 1325-1334.

PRENDERGAST, J.R., QUINN, R.M., LAWTON, J.H., EVERSHAM, B.C. \& GibBONS, D. W. 1993. Rare species, the coincidence of diversity hot spots and conservation strategies. Nature 356, 335-337.

PURVIS, A. \& HeCTOR, A. 2000. Getting the measure of biodiversity. Nature 405, 212-219. 
RAUP, D.M. 1979. Size of the Permo-Triassic bottleneck and its evolutionary implications. Science 206, 217-218.

RAUP, D.M. \& SEPKOSKI, J.J. 1984. Periodicity of extinction in the geologic past. Proceedings of the National Academy of Science 81, 801-805.

REID, W.V. 1998. Biodiversity hotspots. Trends in Ecology and Evolution 13, 275-280.

Reyers, B., VAN JAARSVELD, A.S. \& Kruger, M. 2000. Complementarity as a biodiversity indicator strategy. Proceedings of the Royal Society of London. Series B: Biological Sciences 267, 505513.

Rogers, S.I., ClARKE, K.R. \& REYNOLDS, J.D. 1999. The taxonomic distinctness of coastal bottom-dwelling fish communities of the north-east Atlantic. Journal of Animal Ecology 68, 769-782.

Rouse, G.W. \& FAUCHALD, K. 1997. Cladistics and polychaetes. Zoologica Scripta 26, 139-204.

Rouse, G.W. \& PleiJel, F. 2001. Polychaetes. Oxford University Press, Oxford.

Roy, K., Jablonski, D. \& VAlentine, J.W. 1996. Higher taxa in biodiversity studies: Patterns from eastern Pacific marine molluscs. Philosophical Transactions of the Royal Society of London. Series $B$, Biological Sciences 351, 1605-1613.

RYTI, R.T. 1992. Effect of the focal taxon on the selection of nature reserves. Ecological Applications 2, 404-410.

SEPKOSKI, J.J. 1992. A Compendium of Fossil Marine Animal Families. Second edition. Milwaukee Public Museum, Milwaukee.

SHANNON, C.E. \& WEAVER, W. 1949. The Mathematical Theory of Communication. University of Illinois Press, Urbana.

Sibley, C.G. \& AhlQuist, J.E. 1990. Phylogeny and Classifications of Birds. Yale University Press, New Haven-London.

Solé, R.V., Manrubia, S.C., Benton, M.J. \& BAK, P. 1997. Selfsimilarity of extinction statistics in the fossil record. Nature $\mathbf{3 8 8}$, 764-767.

Stevens, P.F. 1994. The Development of Biological Systematics. Columbia University Press, New York.

STEVENS, P.F. 1997. How to interpret botanical classifications - suggestions from history. BioScience 47, 243-250.

TARDIFF, B. \& DESGRANGES, J.-L. 1998. Correspondence between bird and plant hotspots of the St Lawrence River and influ- ence of scale on their location. Biological Conservation 84, 5363.

Terlizzi, A., Bevilacqua, S., Fraschetti, S. \& Boero, F. 2003. Taxonomic sufficiency and the increasing insufficiency of taxonomic expertise. Marine Pollution Bulletin 46, 556-561.

Thompson, B. W., Riddle, M. J. \& StARK, J. S. 2003. Cost-efficient methods for marine pollution monitoring at Casey Station, East Antarctica: the choice of sieve mesh-size and taxonomic resolution. Marine Pollution Bulletin 46, 232-243.

VANE-WRight, R.I., HuMPHRIES, C.J. \& WILliams, P.H. 1991. What to protect? Systematics and the agony of choices. Biological Conservation $\mathbf{5 5}, \mathbf{2 3 5 - 2 5 4 .}$

van JaARsveld, A.S., Freitag, S., Chown, S.L., Muller, C., Koch, S., Hull, H., Bellamy, C., KRÜGER, M., ENDRÖDY-YounGa, S., MANSELl, M.W. \& SCHOLTZ, C.H. 1998. Biodiversity assessment and conservation strategies. Science 279, 2106-2108.

VÀSQUEZ, D.P. \& GITTLEMAN, J.L. 1998. Biodiversity conservation: Does phylogeny matter? Current Biology 8, 379-381.

WALKER, P.A. \& FAITH, D.A. 1995. DIVERSITY-PD: Procedures for conservation evaluation based on phylogenetic diversity. Biodiversity Letters 2, 132-139.

WALTERS, S.M. 1961. The shaping of angiosperm taxonomy. New Phytologist 60, 74-84.

WARWICK, R.M. 1988. The level of taxonomic discrimination required to detect pollution effects on marine benthic communities. Marine Pollution Bulletin 19, 259-268.

WARWICK, R.M. \& CLARKE, K.R. 1995. New ‘biodiversity’ measures reveal a decrease in taxonomic distinctness with increasing stress. Marine Ecology Progress Series 129, 301-305.

Williams, P.H. \& GASTON, K.J. 1994. Measuring more of biodiversity: can higher-taxon richness predict wholesale species richness? Biological Conservation 67, 211-217.

Williams, P.H., HuMPHRIES, C.J. \& VANE-WRIGHT, R.I. 1991. Measuring biodiversity: taxonomic relatedness for conservation priorities. Australian Systematic Botany 4, 665-679.

Willis, J.C. 1922. Age and Area. Cambridge University Press, Cambridge.

ZWICKL, D.J. \& HILLIS, D.M. 2002. Increased taxon sampling greatly reduces phylogenetic error. Systematic Biology 51, 588-598. 